\title{
SYSTEMS ANALYSIS FOR ENERGY SYSTEMS USING AN INTEGRATED MODEL OF GIS AND TECHNOLOGY MODELS
}

\author{
H. HAMASAKI \\ Fujitsu Research Institute and Centre for International Public Policy Studies, Japan.
}

\begin{abstract}
This paper focuses on large-scale renewable electricity production and aims to identify key factors which affect renewable energy popularization, Japan's carbon emissions, energy independence, and system costs. Based on these factors, we will propose a new energy system for an alternative energy era, using a detailed subregional electricity technology model, the Japan Multi-regional Transmission (JMRT) model. Intermittency and geographical sensitivity are the two main factors that differentiate renewable electricity from conventional sources. Seasonal and diurnal variations in wind/solar electricity necessitate the use of backup capacity and storage. Furthermore, the most renewable source in Japan - onshore wind - has better potential in regions with low electricity demand. This makes integrating the more or less isolated (10) grids of Japan a very important issue. The JMRT model employs $1 \mathrm{~km}^{2}$ grid GIS information on wind speeds, distances from the nearest road and from electricity grid for a very detailed description of wind potential.

This project uses a systems analysis approach, which is the dissection of a system into its component pieces to study how those pieces interact and work together.

Keywords: GIS, renewable energy, technology model.
\end{abstract}

\section{INTRODUCTION}

Japan currently faces many energy-related issues, of which energy independence and carbon emissions are two important policy targets. Most of the fossil fuels used in Japan are imported, and the country's energy self-sufficiency rate is a mere $4 \%$ (18\% if nuclear power is included). The Fukushima disaster made the situation much worse by eliminating the nuclear option, which could have played a significant role in achieving both objectives for the country. Furthermore, the disaster has created a much more urgent and important objective, i.e. maintaining a reliable and economically viable energy supply for its people and industry, as across the nation nuclear plants are being shut down with immediate effect. Japan's electricity production mix is shown in Fig. 1. The 25\% share of nuclear will be almost entirely met by fossil fuels - mainly LNG - over the short term. The current situation has worsened in terms of both self-sufficiency of energy and $\mathrm{CO}_{2}$ emissions.

Fossil fuel thermal power stations with CCS (carbon capture and storage) and renewable energies can help in the climate objective, but only renewables would begin to move Japan towards selfsufficiency.

The objective of this paper is to characterize the renewable potential in Japan and to study its interactions with competitors under some key policy and technology scenarios.

\section{BOTTOM-UP MODEL (JAPAN MULTI-REGIONAL TRANSMISSION (JMRT) MODEL)}

The bottom-up model used for this research, the JMRT model, is a detailed disaggregate Japanese electricity generation system model based on TIMES to reflect factors which affect the popularization of renewables. The TIMES objective is to minimize the total cost of the system, properly augmented by the 'cost' of lost demand. All cost elements are appropriately discounted to a selected year [1]. 


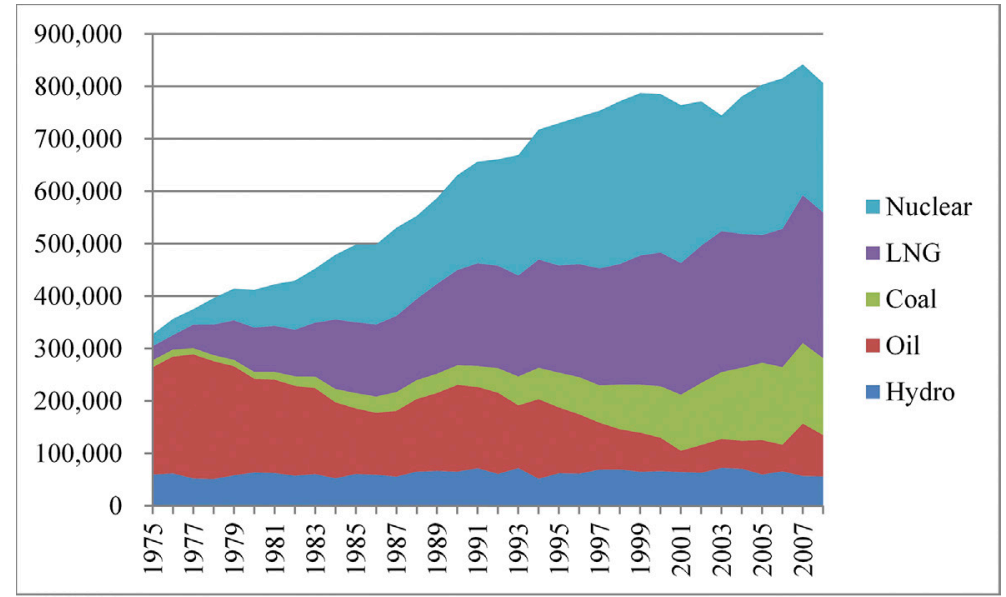

Figure 1: Japanese electricity mix (TWh). Source: The Institute of Energy Economics (2011), Handbook of Energy \& Economic Statistics in Japan.

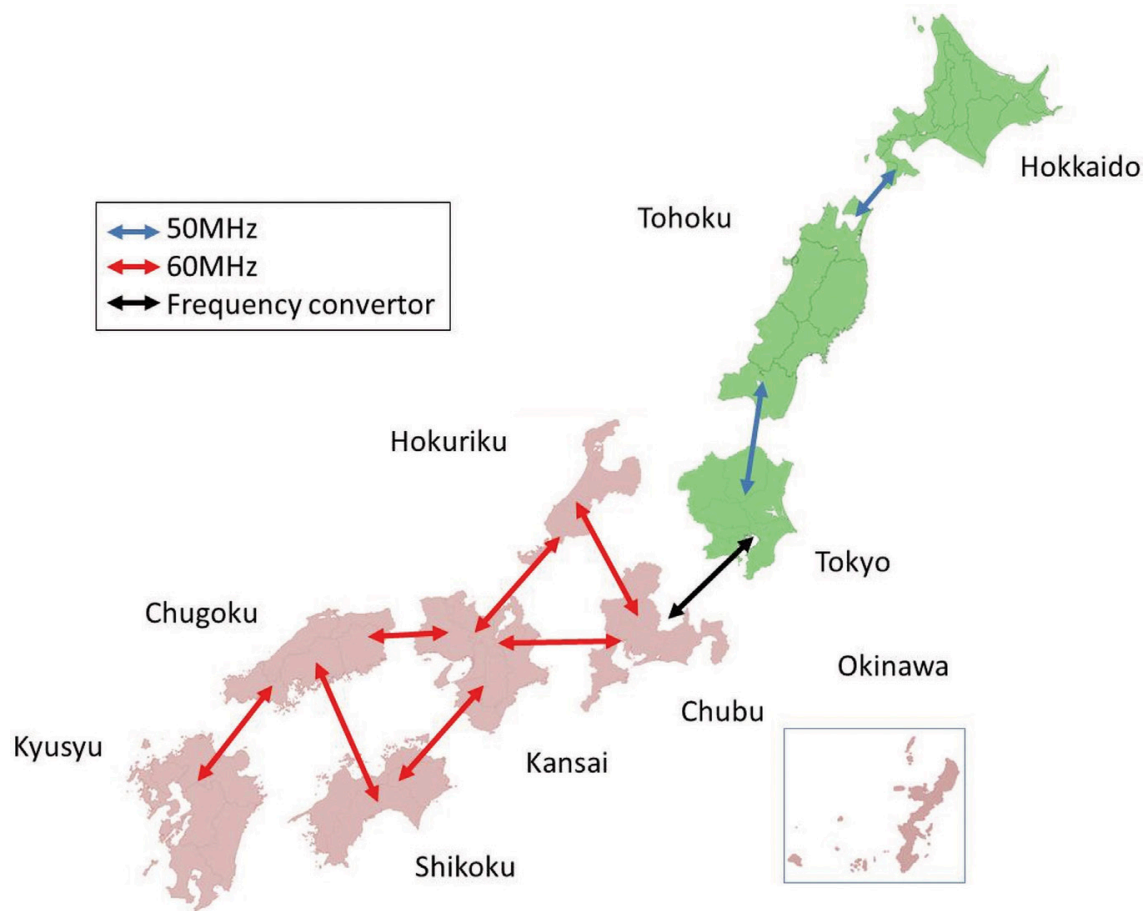

Figure 2: Grid system in Japan.

\subsection{Model structure}

Japan has 10 electricity grids with weak connections between grids as shown in Fig. 2. In addition, there are two different electricity frequencies, 50 and $60 \mathrm{~Hz}$, with frequency converters to convert one frequency to another as shown. 
Figure 3 represents the energy system used in the model. The model focuses mainly on electricity supply, with existing power stations and pumped storage data included therein. The model assumes conventional power stations (Ultra-super Critical, Integrated Gasification Combined Combustion, Gas Turbine Combined Cycle, and nuclear) and renewables (biomass, on-shore and off-shore wind turbine, photovoltaic (PV), geothermal and small hydro) as new technologies. We use cost data of conventional power station of Committee of Electricity Generation Cost Verification [2] and IEA/ NEA [2,3].

\subsection{Database JMRT model}

To build a renewable potential database for the JMRT model, we use MoE potential data [4] and make the following modifications.

In the case of offshore wind, we add GIS calculated data, distance from the nearest infrastructure and sea depth, and also new data sets calculated using GIS data and GIS data for each mesh (Fig. 4).

For TIMES, we make clusters categorized by investment cost and availability factor, and the same clusters are applied to each prefecture. The upper limit of capacity installed in each cluster is applied based on the GIS data set as shown in Fig. 5.

\section{SIMULATION}

\subsection{Simulation scenarios}

In this paper, we employ systems analysis, a powerful tool for identifying the interactions between complex factors. We take two important policy objectives as factors, i.e. nuclear stop and grid expansion, and we multiply them with different levels of carbon reduction and energy dependence on import(Fig. 6). The total number of simulations is 96.

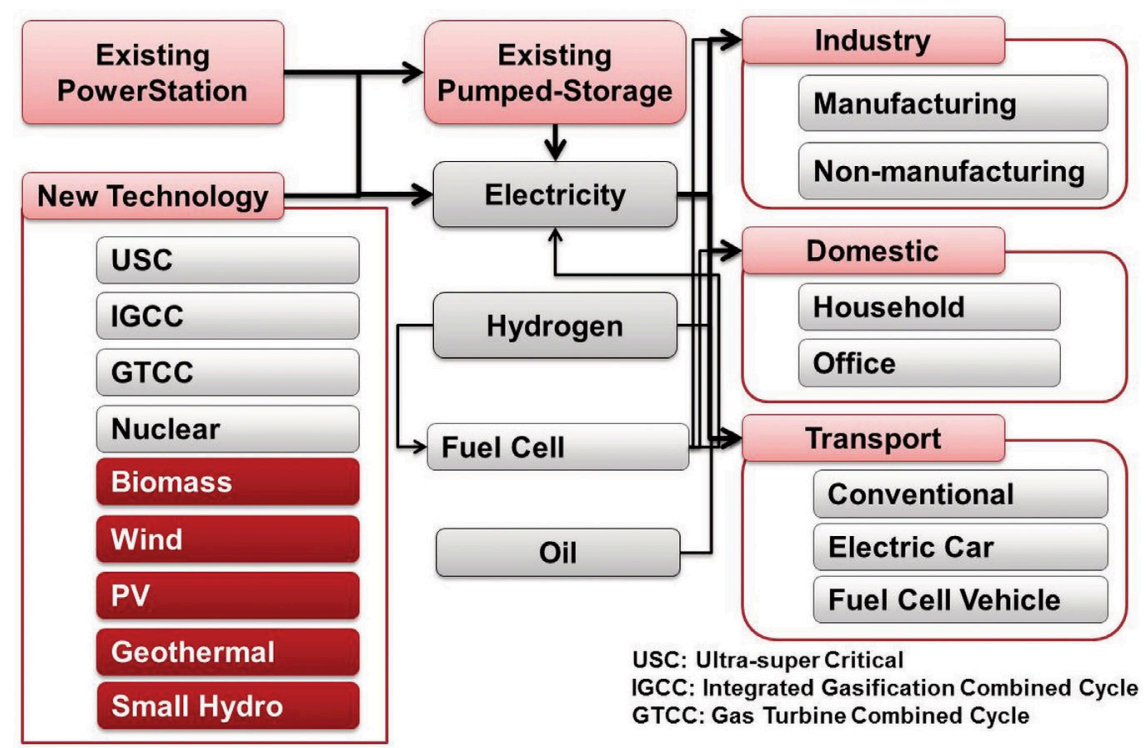

Figure 3: Energy system in JMRT. 


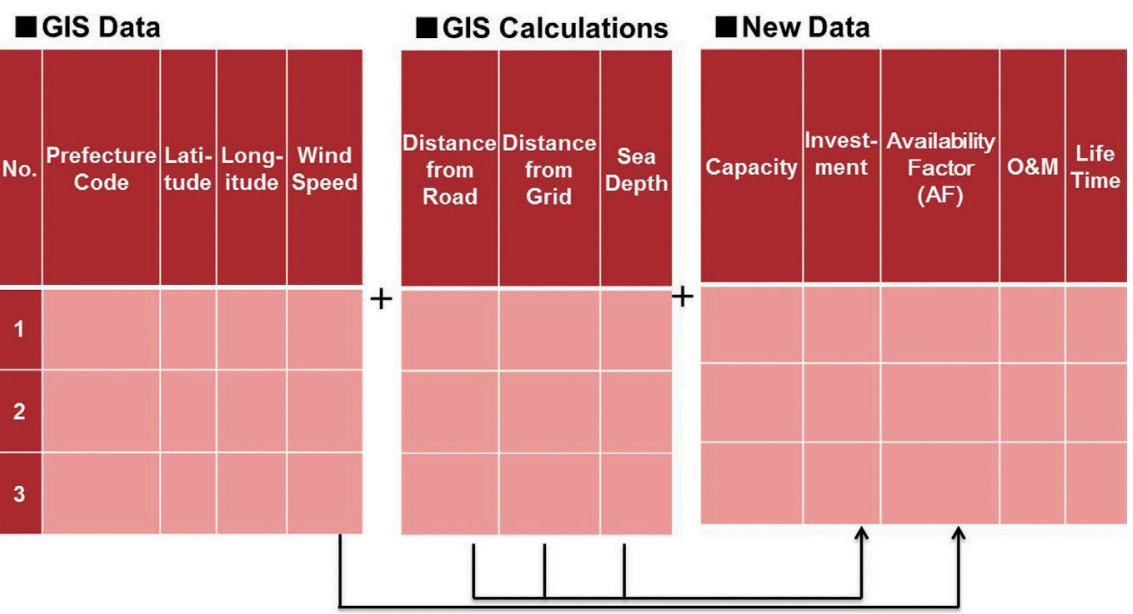

Figure 4: MOE GIS data and new data (case of off-shore wind).

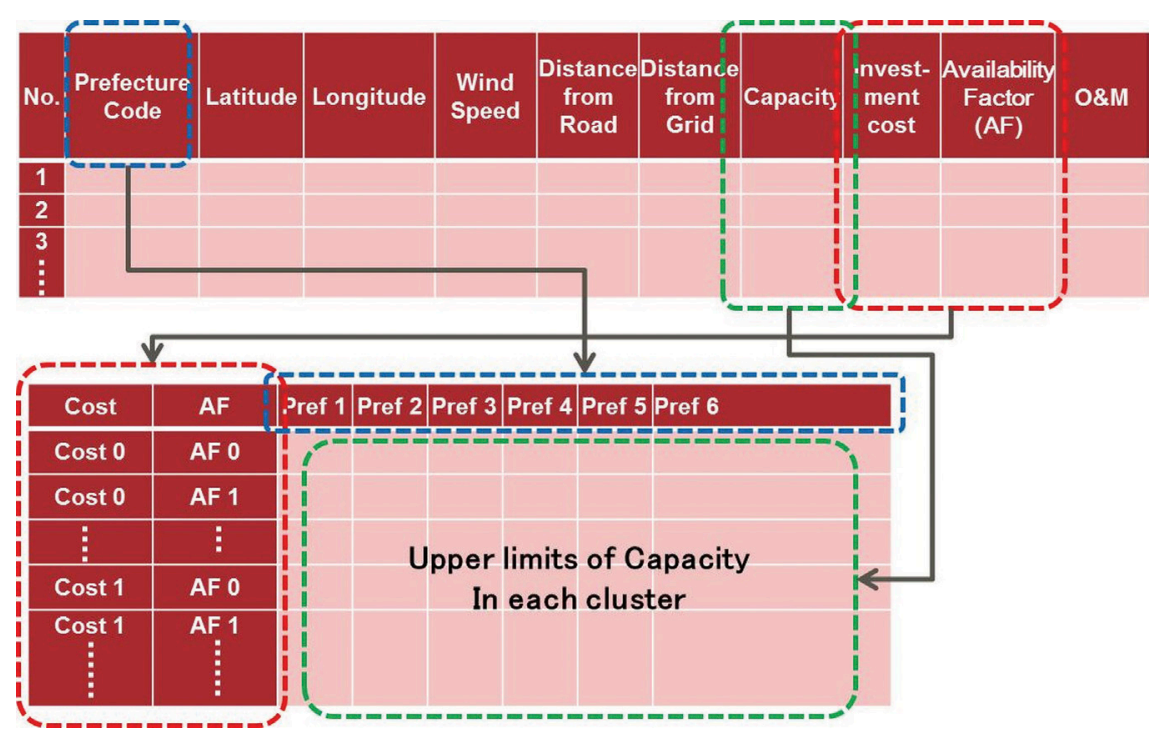

Figure 5: Conversion GIS data to TIMES.

\subsection{Realistic cost curve}

The supply curves shown in Fig. 7 have been computed using used $1 \mathrm{~km}^{2}$ mesh GIS data for onshore and offshore wind, and prefectural data for solar PV. More than 1,000 TWh seem be available for well under 15 cents/kWh based on this figure. However, these costs and availabilities ignore very important spatial and temporal issues, which we propose to address using systems analysis.

There are two main reasons why the actual availabilities would turn out lower and prices would turn out higher, as shown in Fig. 8. 

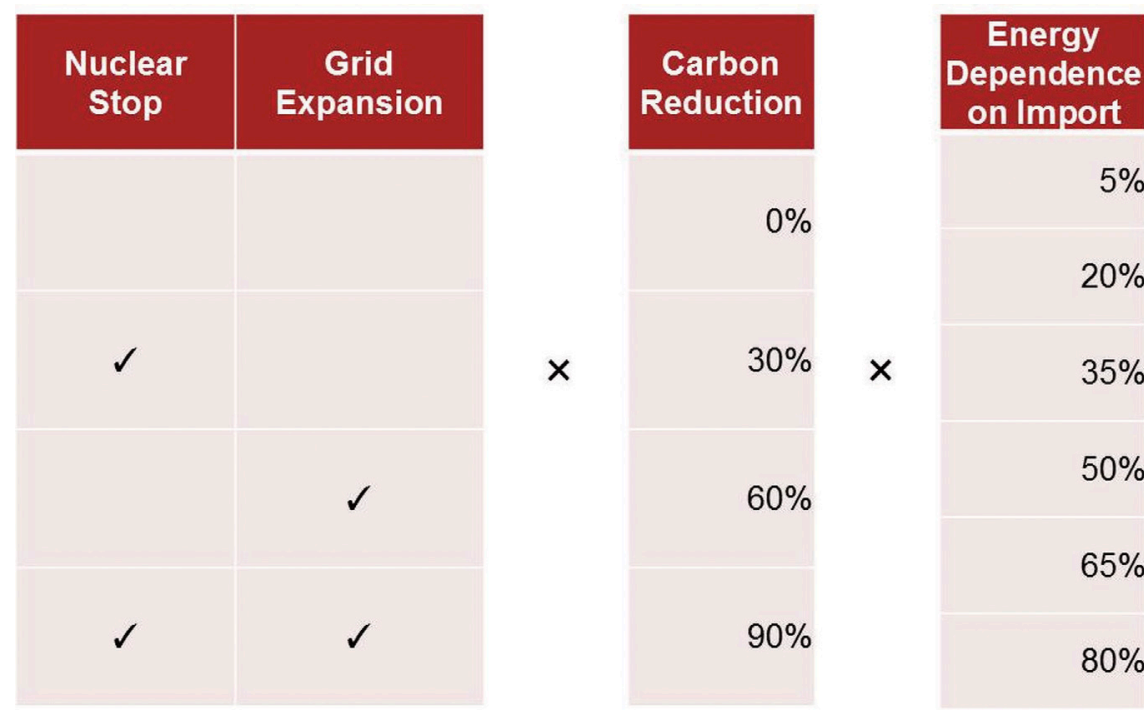

Figure 6: Design of systems analysis.

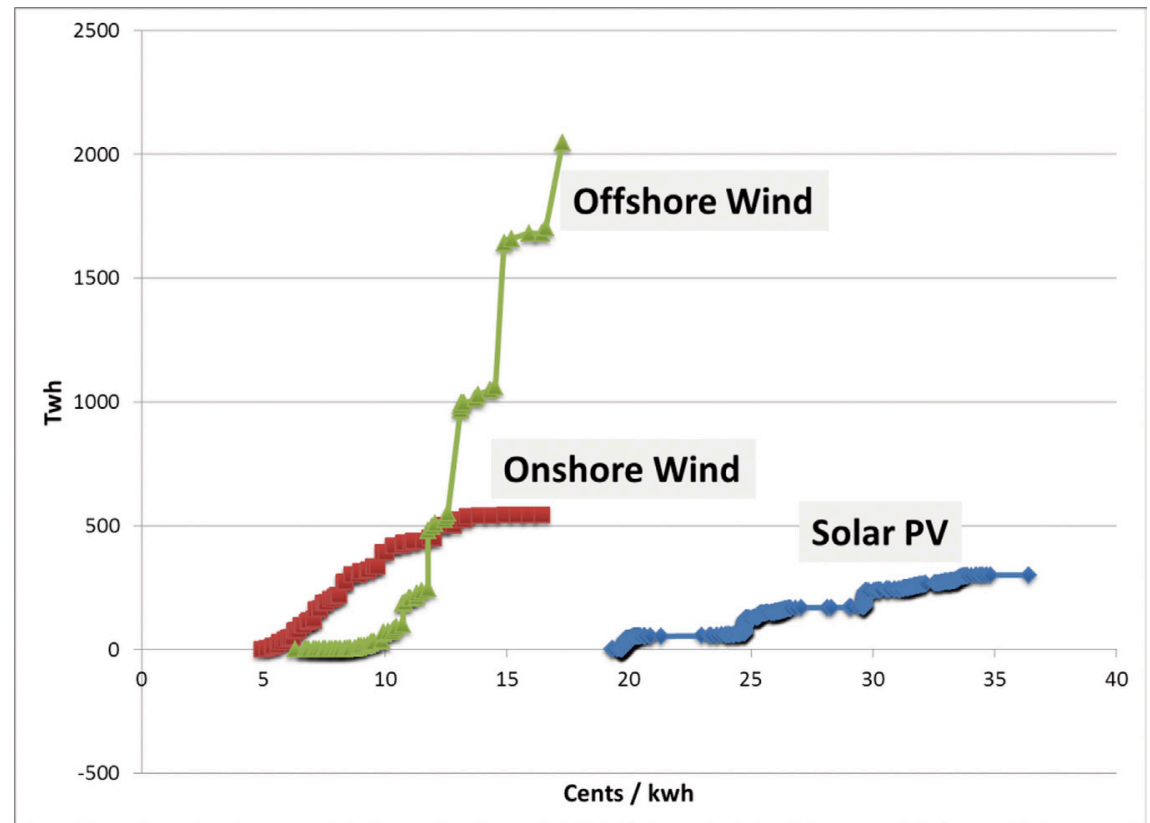

Figure 7: Supply curves of renewable energies.

- The Japanese electricity system comprised 10 grids with very poor interconnections. While the costs of connecting to the regional grids are included in the above estimates, the costs of increasing inter-regional connections are not. Renewable potential is not sufficiently high on the grids in regions that have high demand. Therefore, using the lower part of the above curves necessitates grid expansion. 


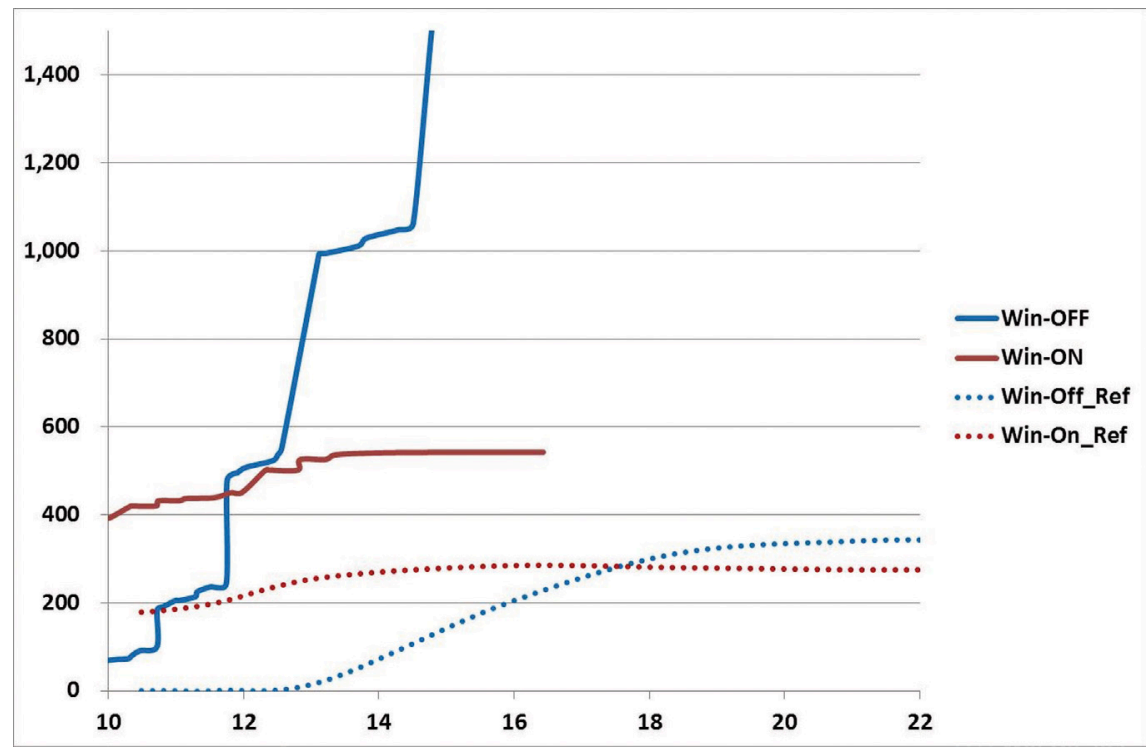

Figure 8: Realistic cost curves under current Japanese electricity system. Note: Win-OFF: potential of offshore wind, Win-ON: potential of onshore wind, Win-Off_Ref: reference of offshore wind, Win-On_Ref: reference of onshore wind.

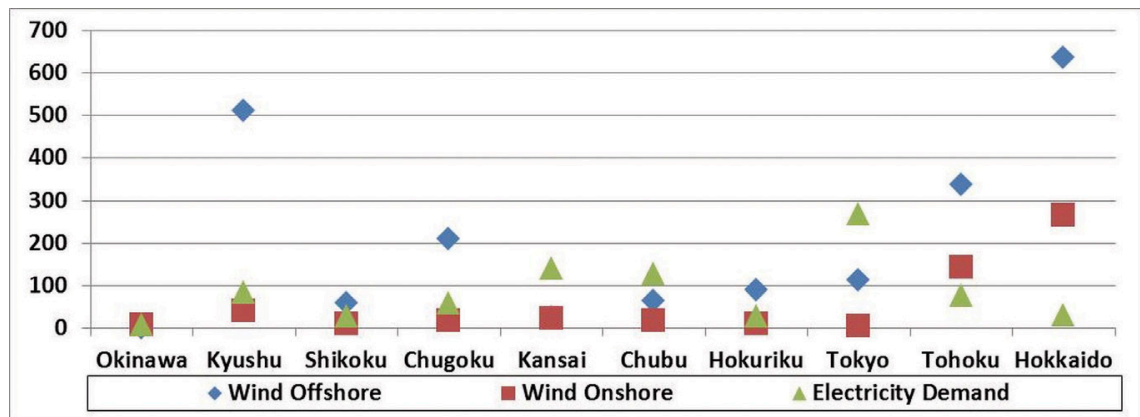

Figure 9: Energy consumption and wind potential in each grid.

- The above prices assume full utilization of power when it is available. However, due to seasonal and diurnal variations in demand, this is not possible, and the actual utilization turns out lower than the potential.

Figure 9 shows energy and wind potential in each grid. Huge wind potential is evident in Hokkaido and Kyushu, but significant electricity consumption can be seen in Tokyo: in a word, there is a sizeable geological gap between wind potential and electricity consumption. Due to the limited connections between regions, it is impossible to make the most use of huge onshore wind potential in Hokkaido.

Grid expansion would make it possible to access and build wind turbines at sites with good wind conditions, and as a result, the actual availability would be even greater than the reference case, as shown in Fig. 10. 


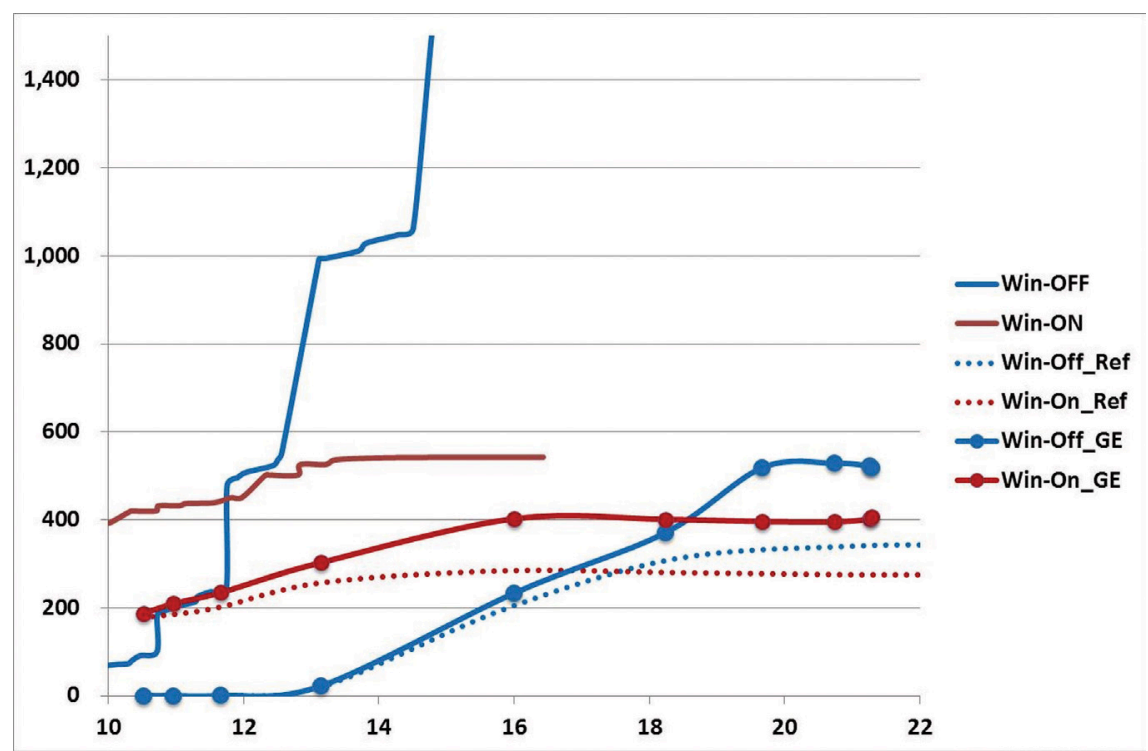

Figure 10: Comparison of cost curves of potential, actual, and grid expansion. Note: Win-OFF: potential of offshore wind, Win-ON: potential of onshore wind, Win-Off_Ref: reference of offshore wind, Win-On_Ref: reference of onshore wind, Win-Off_GE: grid expansion case of offshore wind, Win-On_GE: grid expansion case of onshore wind.

\section{CONCLUSIONS}

In this study, we have used a very detailed representation of Japan's current electricity system, along with very rich data on renewable potential, to explore the interplay between various electricity options for Japan. This work could be useful for policy makers as well as modellers. Modellers, who operate at a higher level of disaggregation than what we have shown in this paper, could use the deployment patterns exposed here as a reference. Quantitative estimates of the impacts of various policy options on primary objectives could be useful for policy makers.

As has been explained above, Japan is now facing a challenge which no other country has faced before: to raise its energy self-sufficiency ratio and reduce GHG simultaneously, even though most of its fossil fuel supply comes from overseas and it cannot depend upon nuclear power. Though these issues cannot be solved by existing technology, our analysis shows what needs to be done in the short term using existing technology and what direction R\&D for new technology should pursue over the long term. In the near future, Japan should integrate all of its electricity transmission lines and create a single grid. Doing so would enable the country to maximize the use of cheaper renewable energy sources and increase the overall efficiency of their usage. CCS at coal-fired thermal power stations could be better utilized as well. A Feed-in Tariff system, which assures suppliers of renewable energy sources that the energy will be purchased at a fixed price, was introduced in 2012 in Japan to encourage utilization of renewable energy sources. However, with separated transmission networks, such a system could in fact raise the price of renewables and thus even be an impediment to their spread.

In the long run, even with a single grid it would be impossible to achieve a stable supply of wind and solar power as provided by Mother Nature. There would be a variety of views upon the extent to which renewable energy sources could be introduced because of their technological constraints. 
Japan would need extra facilities to meet demand at peak times in order to achieve a sufficient supply of electricity generated from renewables. In this research, we suggest the hydrogen cycle as an innovative concept, and the simulation results show that the hydrogen cycle could play a major role in achieving extreme carbon constraint and high energy independency by 2050 .

\section{REFERENCES}

[1] Loulou, R., Remne, U., Kanudia, A., Lehtila, A. \& Goldstein, G., Documentation for the TIMES Model PART I. Energy Technology Systems Analysis Programme, 2005.

[2] Committee of Electricity Generation Cost Verification, National Policy Unit, Cabinet Secretariat, Japan, Committee of Electricity Generation Cost Verification Report, 19 December 2011.

[3] IEA/NEA, Projected Costs of Generating Electricity, 2010, IEA/NEA.

[4] Ministry of the Environment, Renewable Energy Potential Survey Report, 2011, Ministry of the Environment. 